http://dx.doi.org/10.30681/23588403v12i039103

\title{
RELAÇÕES SOCIAIS E O SISTEMA CAPITALISTA NA NARRATIVA O SOFÁ ESTAMPADO, DE LYGIA BOJUNGA NUNES
}

\author{
Juliane Oscar de Souza MOURA (UNEMAT) ${ }^{1}$ \\ Data de recebimento: 09/03/2018 \\ Aceite: 16/08/2018
}

\begin{abstract}
Resumo: Este trabalho tem como objeto de análise a narrativa $O$ Sofá Estampado da autora Lygia Bojunga Nunes. Pretende-se estabelecer discussão em torno das relações sociais, a fim de identificar os valores capitalistas dos indivíduos e suas interferências nos espaços de convivência na sociedade pós-moderna. Foram adotadas como base metodológica pesquisas bibliográficas que possibilitaram fazer uma abordagem aos seguintes assuntos: o individualismo patrimonial; as modificações do espaço-tempo; a identidade consumista e as atitudes humanas politizadas. Com os dados confrontados, verificou-se que as práticas que se destinam a solucionar a problemática da diferença são restritas, visto que as ações diárias estão arraigadas ao aspecto material vindo a naturalizar as crises socioculturais, o que exalta a necessidade de intensificar as atitudes de solidariedade humana.
\end{abstract}

Palavras-chave: Sociedade pós-moderna. Capitalismo. Relações sociais.

Abstract: This work has as object of analysis the narrative $O$ Sofá Estampado (The chintz sofa) of the author Lygia Bojunga Nunes. It is intended to establish a discussion about social relationships in order to identify the capitalist values of individuals and their interference in the spaces of coexistence in postmodern society. Bibliographical research was adopted as a methodological basis, making it possible to approach the following subjects: The patrimonial individualism; The modifications of space-time; Consumer identity and politicized human attitudes. With the confronted data, it was verified that the practices which are intended solving the differences problematic are restricted, since daily actions are deeply rooted in the material aspect, thus naturalizing the socio-culturais crises, which exalts the need to intensify attitudes of human solidarity.

Keywords: Postmodern society. Capitalism. Social relationships.

\section{Introdução}

O sistema capitalista brasileiro na sociedade contemporânea busca atender a proposta de modernização tanto na área rural como na área urbana na tentativa de se adequar as exigências comerciais para aumentar a produtividade e ampliar o mercado consumidor. De

\footnotetext{
${ }^{1}$ Mestranda do Programa de Pós-Graduação em Letras da Universidade Estadual de Mato Grosso - UNEMAT, campus de Sinop, Graduada em Licenciatura em Pedagogia para a Educação Infantil pela Universidade Federal de Mato Grosso. Nova Santa Helena-MT, Brasil. Email: juoscarmoura@ hotmail.com
} 


\section{Revista de Estudos Acadêmicos de Letras}

modo geral, o espaço de vivência se transformou em espaço de negócio cujo parâmetro está alicerçado na concentração de capital.

Como forma de alcançar a discussão das relações sociais foram realizadas pesquisas bibliográficas que oportunizaram fazer uma abordagem à organização da sociedade pautada no sistema capitalista, bem como às modificações do espaço-tempo em função do acúmulo de bens, à identidade consumista produzida pela mídia através de métodos persuasivos que convencem e transformam o ser pensante em um ser alienado e manipulado e às atitudes humanas politizadas por merecer destaque por serem agentes facilitadores da construção de uma sociedade humanizadora.

A escolha do recorte temático: as relações sociais e o capitalismo na narrativa $O$ Sofá Estampado se faz necessária, uma vez que a obra tematiza essas relações. Com o processo de globalização crescente em período de pós-modernidade as relações estão ficando empobrecidas, pois as pessoas estão atribuindo valor demasiado aos bens materiais vindo a deixar em segundo plano as relações afetivas o que consequentemente causa uma felicidade momentânea assumindo posteriormente um caráter de frustração emocional e psicológica.

\section{O desenvolvimento do capitalismo e o processo de modernização}

$\mathrm{O}$ advento da produção em larga escala mecanizada ocorreu primeiramente na Inglaterra nos séculos XVIII e XIX, depois se estendeu por várias localidades, com o objetivo de elevar a produtividade das empresas, conquistar o comércio internacional e obter maiores lucros.

Por efeito, com o golpe militar de 1964, o Brasil passou a viver uma fase de modernização mais acelerada "com isso, certas frações da classe média brasileira desfrutam de um desafogo econômico temporário, ao mesmo tempo que o arrocho salarial aperta as classes mais baixas." (LAJOLO e ZILBERMAN, 2002, p. 127). As mudanças ocorridas a fim de incentivar o crescimento econômico não foram suficientes para abolir as disparidades existentes na sociedade.

Ademais, as manifestações sociais, que visavam a implantação da democracia, aliadas a necessidade do Estado apresentar externamente uma imagem mais democrática, para fortalecer a posição de exportadores a certos países com partidos liberais no poder, promoveram o declínio do governo militar. (LAJOLO e ZILBERMAN, 2002, p. 128).

Os ideais capitalistas perpassaram as formas de governo que se instalaram no país, 
pois na contemporaneidade também estão voltados a atender os interesses de mercado que venham a garantir a expansão das fronteiras econômicas, políticas, entre outras. Pautando-se na visão marxista o autor Giddens (1991, p. 20) expõe:

A ordem social emergente da modernidade é capitalista tanto em seu sistema econômico como em suas outras instituições. O caráter móvel, inquieto da modernidade é explicado como um resultado do ciclo investimento-lucroinvestimento que, combinado com a tendência geral da taxa de lucro a declinar, ocasiona uma disposição constante para o sistema se expandir.

Seguindo esse viés, para atender as exigências mercadológicas, o mercado de trabalho passou a se configurar como um divisor de águas entre a classe trabalhadora e a classe dominante, pois de um lado se faz necessária à mão de obra e do outro lado os donos dos meios de produção. (MARX, 1982). Por consequência, o capitalista passou a comprar a baixo custo a força de trabalho da classe operária. A autora Quintaneiro et al. (2002, p. 48) faz comentários adicionais sobre as relações de trabalho na sociedade capitalista:

[...] o valor que é produzido durante o tempo de trabalho excedente ou nãopago é apropriado pela burguesia. Parte desse valor extraído gratuitamente durante $\mathrm{o}$ processo de produção passa a integrar o próprio capital, possibilitando a acumulação crescente. (QUINTANEIRO et al., 2002, p. 48).

As condições determinantes para a expansão do capital passaram a impor ao operário a venda da força de trabalho transformando-a em mercadoria barata. A exploração da classe proletária é decorrente do seu pensamento e conduta alienada, que na maioria das vezes, não favorece à compreensão de como se dá efetivamente todo o processo. Assim,

[..] O trabalhador converte-se numa mercadoria tanto mais barata quanto mais mercadorias produz. A desvalorização do mundo humano cresce na razão direta da valorização do mundo das coisas. $\mathrm{O}$ trabalho não apenas produz mercadorias, produz também a si mesmo e ao operário como mercadoria, e justamente na proporção em que produz mercadorias em geral. (MARX apud QUINTANEIRO et al., 2002, p. 25).

Durante muito tempo, as teorias marxistas apresentadas acima foram utilizadas para explicar a organização social capitalista. Os donos dos meios de produção se constituíam como a classe dominante, a eles competia fazer o uso da razão de forma prudente de acordo com suas próprias ideologias, para determinar as ações que seriam executadas, enquanto aos operários restava-lhes, apenas, a prestação de serviços. 


\section{Revista de Estudos Acadêmicos de Letras}

Por pelo menos 200 anos foram os administradores das empresas capitalistas que dominavam o mundo - isto é, separaram o factível do implausível, o racional do irracional, o sensato do insensato, e de outras formas ainda determinaram e circunscreveram a gama de alternativas dentro das quais confinar a trajetória da vida humana. Era, portanto, sua visão do mundo, formado e reformado à imagem dessa visão, que alimentava e dava substância ao discurso dominante. (BAUMAN, 2001, p. $66-67$ ).

Sobretudo, surgiram linhas teóricas que passaram a defender a existência de novas divisões no sistema capitalista como: o capitalismo pesado e o capitalismo leve. "O capitalismo pesado era o mundo dos que ditavam as leis, dos projetistas de rotinas e dos supervisores." (BAUMAN, 2001, p. 75). Cada classe tinha podemos dizer a "sua trajetória estabelecida de maneira clara, sinalizada ao longo de todo o percurso e pontuada por acontecimentos." (BAUMAN, 2005, p. 56). Assim, tudo era determinado, um operário nunca chegaria a ser burguês e vice-versa.

Mas a modernidade fez surgir à era do capitalismo leve não aboliu as autoridades que ditam as leis, nem as tornou dispensáveis, "apenas permitiu que coexistissem autoridades em números tão grandes que nenhuma poderia se manter por muito tempo e menos ainda atingir a posição de exclusividade." (BAUMAN, 2001, p. 76). Estamos agora passando da fase "sólida" da modernidade para a fase "fluída", uma vez, que nada consegue manter a forma por muito tempo. Bauman (2005, p. 58) complementa que:

Não se deve esperar que as estruturas, quando (se) disponíveis, durem muito tempo. Não serão capazes de aguentar o vazamento, a infiltração, o gotejar, o transbordamento - mais cedo que se possa pensar, estarão encharcadas, amolecidas, deformadas e decompostas. Autoridades de hoje respeitadas amanhã serão ridicularizadas, ignoradas e desprezadas. (BAUMAN, 2005, p. $58)$.

Com as discussões apresentadas, verificou-se que o sistema capitalista passou por constantes transformações. Diante disso, o ato de relacionar-se veio a se tornar, ainda mais, conflituoso, pois as pessoas tiveram que reorganizar os seus modos de vida em um espaço/tempo indeterminado.

\subsection{O processo de modernização e as produções literárias do gênero infantojuvenil}

Com o processo de modernização desencadeado com maior rigor no governo militar buscou-se transformar a socideade capitalista brasileira em um modelo mais evoluído, as 
medidas adotadas para alcançar o objetivo almejado se estenderam ao departamento cultural, na qual passaram a ser realizados investimentos que possibilitassem o aprimoramento das instituições responsáveis pela política de cultura do Estado. Para maiores esclarecimentos Lajolo e Zilberman expõe:

Os anos 60 e 70 assistem à implantação de uma nova etapa da sociedade brasileira em direção a um modelo capitalista mais avançado, o que implica uma inversão maior de capitais na produção cultural, bem como o aprimoramento de instituições às quais compete a execução da política cultural do Estado. (LAJOLO e ZILBERMAN, 2002, p. 158).

O contexto apresentado favoreceu o crescimento das produções literárias, bem como da literatura infantil que manteve traços das tendências passadas com caráter pedagógico, mas também houveram esforços para ocorrer renovações no que tange aos objetivos do texto. Esse processo de renovação acarreta ainda a produção de textos autoconscientes, isto é, "[...] textos que explicitam e assumem sua natureza de produto verbal, cultural e ideológico. Reside aí o ponto de radicalidade mais extrema a que chega o texto infantil das duas últimas décadas." (LAJOLO e ZILBERMAN, 2002, p. 160).

Ao romper com o pedagogismo, as produções literárias destinadas às crianças passam a abordar assuntos pertencentes ao meio social utilizando-se de elementos fantásticos e maravilhosos com isso, após ter conquistado a duras penas o direito de "[...] falar com realismo e sem retoques da realidade histórica, e ao mesmo tempo que redescobre as fontes do fantástico e o imaginário, a literatura infantil contempla-se a si mesma em seus textos." (LAJOLO e ZILBERMAN, 2002, p. 160).

A tendência inovadora surgiu com o intuito de possibilitar ao leitor criança e jovem a compreensão do meio fluído em que os mesmos estão inseridos oferecendo condições para a elaboração de novos significados, bem como a reconstrução de novos sentidos na busca pela sua identidade.

O que ela deseja é explicitar, em um nível possível de ser compreendido pelo leitor criança, as contradições do momento histórico em que vivemos. Com sua perfeita integração no universo psicológico e linguístico desse receptor especial permite que, através da literatura, ele possa ter uma visão bastante clara dos comportamentos sociais e inicie uma caminhada que vai da fantasia ao domínio da lógica. (SANDRONI, 1987, p. 73).

Nessa linha de inovação das produções literárias pode-se destacar pela sua capacidade inventativa e alto teor artístico a autora Lygia Bojunga Nunes, que começou a escrever quando 


\section{Revista de Estudos Acadêmicos de Letras}

a ditadura militar ainda dominava o Brasil. Foi a primeira escritora, fora do eixo Europa-Estados Unidos, a ganhar o Prêmio Hans Christian Andersen, esse prêmio é o mais prestigioso prêmio internacional do gênero, conhecido como Prêmio Nobel da literatura voltada para crianças e jovens.

A literatura produzida pela autora entre os anos 70 à 80 foi recipiente de grandes premiações dentre as quais podemos destacar a obra $O$ Sofá Estampado que permitiu a obtenção do Grande Prêmio APCA de Críticos Autorais; O Melhor para o Jovem (outorgado pela Fundação Nacional do Livro Infantil e Juvenil); Prêmio Bienal Banco Noroeste de Literatura Infantil e Juvenil; participou das obras integrantes do prêmio Andersen; se insere, também, no conjunto das obras que recebeu, em 2004, o prêmio em Memória de Astrid Lindgren.

A narrativa foi galardoada várias vezes por apresentar uma visão questionadora de falsos valores e comportamentos da sociedade capitalista. Ela trata da futilidade, do consumismo, da desumanização do homem, da superação dos conflitos internos, da busca pelo autoconhecimento e pela identidade.

Embora a obra $O$ Sofá Estampado pertença ao gênero infantojuvenil acaba atraindo também o público adulto pela qualidade da sua escrita literária, por facilitar ao indivíduo ampliar a sua visão de mundo e se posicionar diante das mazelas sociais. O leitor, parte integrante de um todo que forma uma sociedade capitalista a partir de suas vivências, estabelece interação com o texto o que contribui para identificar o espaço-tempo do meio em que está inserido e resolver os seus conflitos internos. A autora Sandroni (1987, p. 71) em estudos sobre a abordagem social nas produções literárias detecta que:

Toda obra literária contém elementos de transgressão: instaura a reflexão crítica quando retrata ou representa determinado momento histórico, mesmo sem contestar abertamente seus valores; ou quando, com inovações dos fatos linguísticos, conduz à teoria e à prática de uma escrita que pretende corroer e destruir as convenções, as normas e os valores socio-culturalmente aceitos como característicos da literatura.

Com essa discussão buscou-se deixar claro que não havia investimentos em produções literárias do gênero infantojuvenil até a década de 60 e as poucas obras existentes anteriores a esse período seguiam uma tendência apenas pedagógica. O processo de modernização possibilitou o surgimento de escritores como Lygia Bojunga Nunes, os quais ficaram conhecidos mundialmente pela capacidade de produzir obras que permitam estabelecer relação com o meio social e a partir disso construir e reconstruir valores, significados e sentimentos. 


\section{Análise da narrativa O Sofá Estampado, da autora Lygia Bojunga Nunes}

A obra $O$ Sofá Estampado é composta por 24 capítulos curtos produzidos mediante jogos temporais com idas e vindas do presente para o passado, por isso não cobre evidentemente todo o percurso temporal existente entre o tempo do enunciado e o da enunciação, fazendo-se necessário o leitor, através da sua imaginação, preencher os espaços vazios. Portanto, não há uma linearidade nos acontecimentos.

O ambiente encontrado é o de busca pela identidade, porque Vitor (personagem principal) não se identifica com as práticas capitalistas, fundamentadas na individualidade, e começa a percorrer espaços diversificados na tentativa de realizar descobertas que possam diminuir os seus conflitos internos. Mas, somente no desfecho final consegue se posicionar diante do autoritarismo do pai, da exploração sofrida no mercado de trabalho, da invisibilidade de sua namorada e passa a tomar decisões com base nas suas vontades e desejos, bem como a dedicar-se as lutas minoritárias existentes no meio de convívio.

A narrativa apresenta uma gama de elementos que podem ser facilmente explorados e relacionados com o contexto sociocultural contemporâneo. Há personagens que passam a maior parte do tempo desempenhando atividades para satisfazer suas necessidades materiais e consequentemente acabam por colocar em segundo plano as relações afetivas. Nesse sentido, representam os indivíduos escravizados, dominados e alienados pelo capital na sociedade moderna onde "o tempo se tornou dinheiro depois de se ter tornado uma ferramenta (ou arma?) voltada principalmente a vencer a resistência do espaço: encurtar as distâncias, tornar exequível a superação de obstáculos e limites à ambição humana.” (BAUMAN, 2001, p.130). O dinheiro passou a ser o objeto mais desejado, por possibilitar aos indivíduos a oportunidade de acumular patrimônio, ganhar prestígio e poder.

No desenrolar das histórias vivenciadas por Vítor, surgem espaços urbanos: a cidade do Rio de Janeiro; naturais: a floresta morada primeira do Vítor e a floresta Amazônica; sociais: a casa da Dona-da-casa, a agência Z, a casa do Vítor e a escola; simbólicos como por exemplo: o Sofá, a Mala, a Rua e virtuais: a TV.

Os espaços apresentados representam os ambientes que foram construídos e modificados em função dos anseios de modernidade, que buscam a expansão industrial. Verifica-se nos cenários apresentados, que os personagens vivem em um ambiente criado, um ambiente de ação que, é claro é físico, mas não mais apenas natural. A autora demonstra que 


\section{Revista de Estudos Acadêmicos de Letras}

não só a paisagem construída nas áreas urbanas, "mas a maioria das outras paisagens também se torna sujeita à coordenação e controle humano.” (GIDDENS, 1991, p. 66).

Ademais, observa-se, através das ações dos personagens, que as práticas culturais modernas desestabilizaram o capital sólido que existia dando início ao capital leve, onde tudo é indeterminado. As relações estabelecidas tornaram-se conflituosas, pois a vida dos indivíduos "é uma tarefa não algo determinado, e uma tarefa ainda incompleta, que clama incessantemente por cuidados e novos esforços.” (BAUMAN, 2001, p. 155). A obra permite verificar que o ambiente fluído não apresenta um modelo de vivência para que as pessoas possam seguir já que tudo é muito instável, isso faz gerar crises no plano interno e externo vindo a dificultar a construção da identidade.

Lygia Bojunga Nunes preocupa-se com cada detalhe do enredo, bem como com a caracterização dos personagens e dos espaços sociais, para representar a sociedade moderna. $\mathrm{O}$ personagem principal, por exemplo, que representa o indivíduo contemporâneo a procura da sua identidade é um tatu (Vítor) que todas às vezes que se depara com uma situação conflituosa começa a cavar, abrir túneis na tentativa de encontrar refúgio. Como exemplificado a seguir: De repente, a unha do Vítor desatou a cavar tão depressa, que num instantinho unha, focinho, rabo, o Vítor sumiu no buraco, fazendo pela primeira vez o que a Dalva tinha explicado pra Dona-da-casa: bateu o nervoso, ele cava. (NUNES, 2005, p. 19 - 20).

A autora também construiu personagens secundários, totalmente, individualistas e personagens politizados, comprometidos com as causas sociais. Dentre os personagens considerados individualistas podemos destacar Dr. Ipo, por ser um hipopótamo que não possui tempo para as relações afetivas apenas para os negócios, o personagem mostra a face do capital que reduz seres humanos a meros objetos que podem ser facilmente comercializados ao valor de moeda. Conforme ilustrado no recorte: “-Mas não pode, Dr. Ipo, bicho nenhum pode sair daqui sem fiança. O Ipo puxou livro de cheque, rabiscou número e letra, jogou papel pro ar: Levo elefante, levo essa aqui, levo quem eu quiser, taí o dinheiro. (NUNES, 2005, p. 63).

Em concordância com os valores de Dr. Ipo pode-se destacar a D. Popô, que no desenrolar da narrativa passa por uma transformação em decorrência da competição e da ânsia pelo lucro: de pozinha, ingênua e cheia de ilusões, passa a D. Popô, ambiciosa e individualista: “-Muito bem, vamos lá: a senhora quer transformar a sua mágoa em quê? -Dinheiro. -E a orelha deu uma tremidinha.” (NUNES, 2005, p. 74). Percebe-se que o seu pensar e agir está condicionado ao lucro financeiro.

D. Popô aproveitou-se dos conflitos internos de Vítor para aumentar a lucratividade 
da sua agência publicitária. Com isso, verifica-se que as interações estabelecidas no espaço de trabalho capitalista são temporais e transitórias, por possuir uma permanência em torno da satisfação gerada pelo lucro. De acordo com Bauman (2001, p. 187) a política existente no mercado de trabalho "[...] converge para [...] o enfraquecimento e a decomposição dos laços humanos, das comunidades e das parcerias." Esse cenário pode ser visualizado no seguinte trecho:

\begin{abstract}
-Você vai anunciar um cigarro novo: Status. E assim: você fuma outros cigarros, tudo irrita a sua garganta, você tosse a beça: aí você muda pra Status: não tosse nunca mais. O Vítor quase morreu de tossir pra poder anunciar e fumar o tal de Status. No meio da filmagem, a unha não aguentou: cavou. A Dona Popô deu ordem de aproveitar a cena de cavação pra um comercial de cavadeira elétrica. (NUNES, 2005, p. 80).
\end{abstract}

O Sofá Estampado leva adiante a reflexão sobre as formas de relacionar-se, que mostra a degradação a que pode chegar o indivíduo vítima da exploração capitalista, como ocorre com Vítor completamente consumido pelo marketing publicitário. "Em outras palavras, laços e parcerias tendem a ser vistos e tratados como coisas destinadas a serem consumidas e não produzidas." Por isso, estão sujeitas aos critérios de avaliação de todos os outros objetos de consumo. (BAUMAN, 2001, p. 187). Fica evidente que nas transações de negócios apresentadas não se leva em consideração, muitas vezes, o outro mas sim as vantagens adquiridas nesse processo.

Além disso, existem estratégias de persuasão realizadas através dos diversos meios de propagandas, a mando dos empreendedores, na ânsia de aumentar a rentabilidade e crescer no mercado empresarial. As propalações sobre objetos diversos induzem as pessoas ao consumismo desmedido levando-as a adotar uma nova identidade baseada apenas na futilidade.

O autor Perkin (1981 apud Bauman, 1999, p. 233) tece algumas afirmações sobre as profissões existentes na sociedade capitalista:

[...] vivem da persuasão e da propaganda, alegando que seu serviço específico é indispensável para o cliente ou empregador e para a sociedade e o Estado. Através disso esperam elevar seu status e, assim, seus rendimentos, autoridade e recompensas psíquicas (deferência e autorespeito). $\mathrm{O}$ fato de por vezes o serviço não ser essencial nem eficiente não anula o princípio. Basta que seja assim considerado pelos que o fornecem e os que deles se utilizam.

Em meio a essa teia de subordinação ideológica que leva ao consumismo é oportuno citar a personagem Dona-da-casa que se preocupa apenas com a aparência. Os objetos 


\section{Revista de Estudos Acadêmicos de Letras}

inanimados conquistam primazia, sendo mais valorizado que os seres animados que circundam a casa. Como podemos observar no recorte da obra O Sofá Estampado exposto abaixo:

Dona-da-casa tinha mania de combina: o sapato precisava combinar com o vestido, "ih, que horror, esse vestido não combina com a poltrona, deixa eu ir lá trocar de roupa antes de vir me sentar", a cortina tinha que combinar com o tapete, a poltrona com o sofá, a flor na jarra tinha que combinar com os dois, e se uma coisa não combinava com a outra a Dona-da-casa tinha dor de cabeça. (NUNES, 2005, p. 08).

A participação da Dona-da-casa se resume em fazer combinações de objetos materiais, já a de sua gata Dalva em assiduidade no quesito assistir televisão. Dalva uma gata angorá, passa horas em frente à televisão assistindo a programação e engolindo tudo sem digerir. Como consequência, não há espaço para o diálogo inclusive com o seu namorado Vítor.

Essa situação é inerente ao contexto social, pois grande parcela da população possui dependência midiática. Rossler (2004, p. 110) traz explicações complementares sobre o assunto:

Todavia, quando o indivíduo se torna incapaz de romper com tais formações psíquicas, mesmo nas situações de sua vida em que esses padrões cotidianos de pensar, sentir e agir necessitem ser superados, estamos diante de um fenômeno de alienação. (ROSSLER, 2004, p.110).

Esse fenômeno pode ser facilmente identificado na fala da personagem Dalva, haja visto que o seu pensar e agir são determinados pelos espaços virtuais: “-Alô... Anúncio de cigarro Top: tem um homem lindo dando um beijo enorme numa mulher linda num carro enorme." (NUNES, 2005, p. 53). Com a personagem Dalva a autora demonstra o quanto as pessoas são influenciadas pela mídia na construção das ideologias.

Instrumentos tecnológicos, como a televisão, faz interferências na conduta individual e repercute nas vivências sociais. Logo, é possível identificar impactos negativos, por contribuir com a formação de uma sociedade não leitora, pois o prazer está atrelado, apenas, ao que é visto no veículo de comunicação, não há espaço para outras fontes de lazer, isso limita a visão de mundo, a compreensão do meio em que as pessoas estão inseridas, conforme representado por Dalva: “[...] leu e desabafou pra Dona-da-casa-e-ela: - Não tem figura. Não tem anúncio. Não toca música. Só tem letras que troço difícil!” (NUNES, 2005, p. 09).

Uma estrutura social alienada produz uma vida cotidiana alienada a qual, por 


\section{Revista de Estudos Acadêmicos de Letras}

sua vez, determina o esvaziamento da individualidade humana, impedindo o pleno desenvolvimento dos indivíduos, desenvolvimento esse que requer a existência de condições objetivas e subjetivas favoráveis à apropriação das esferas materiais e simbólicas mais desenvolvidas do gênero humano, com a consequente objetivação individual no interior dessas esferas. (ROSSLER, 2004, p. 110, grifo nosso).

O processo de alienação é uma condição determinante para a manutenção das estruturas sociais. Os indivíduos pensam estar fazendo escolhas por vontade própria, quando na verdade estão apenas consumindo produtos padronizados e aprovados pelo mercado. Bauman (1999, p. 277) salienta que "a cobiçada liberdade do consumidor é, afinal, o direito de escolher 'por vontade própria' um pro-pósito e um estilo de vida que a mecânica supraindividual do mercado já definiu e determinou ao consumidor.” (BAUMAN, 1999, p. 277).

O autor segue explicitando que sem a percepção do estado de subordinação, as pessoas consomem produtos diversificados na tentativa de suprir as carências afetivas, causadas pelas relações empobrecidas e conflituosas. A prática do consumo permite uma sensação de felicidade momentânea.

A defasagem entre estados de felicidade desejáveis e aqueles efetivamente alcançados resulta de um crescente fascínio com as seduções de mercado e a posse de mercadorias; as rodas do mecanismo realimentador da economia voltada ao consumo são assim lubrificadas, enquanto as estruturas políticas e sociais permanecem incólumes e intactas. (BAUMAN, 1999, p. 277).

O fascínio e a sensação de felicidade pela obtenção de mercadorias são fatores decisivos para a consolidação de uma sociedade consumista. Sobretudo, esse processo não é igualitário a todos os indivíduos, visto que existe uma divisão de classe econômica que possibilita privilégios à camada social dominante e restringe a posse de bens materiais à camada menos favorecida. "A condição pós-moderma dividiu a sociedade em metades, a dos felizes seduzidos e a dos pobres oprimidos.” (BAUMAN, 1999, p. 274).

Essa situação não exprime surpresa, mas preocupação, pois, "as coisas que vão mal para algumas pessoas raramente preocupam aqueles que vão bem.” (BAUMAN, 1999, p. 273). É possível conviver com visões diárias de fome, falta de teto, falta de agasalho, de uma vida digna e ao mesmo tempo viver feliz e dormir tranquilamente à noite.

Por isso, a autora busca mostrar com a personagem Avó do Vítor (arqueóloga, ambientalista) algumas atitudes que existem na sociedade, mas que deveriam estar presentes nas ações cotidianas das pessoas, de um modo geral, para haver uma convivência harmônica e 


\section{Revista de Estudos Acadêmicos de Letras}

humana no meio social. A personagem desenvolve um papel politizado engajado na luta política em defesa da ecologia e dos marginalizados. Ela é a representação da importância do saber aberto ao próximo. $\mathrm{O}$ conhecimento partilhado, o intercâmbio de experiências entre os seres adultos, crianças, bichos e etc. são ideias recorrentes na obra. Conforme exemplificado: “-To indo pra Amazônia, estão perseguindo muito bicho por lá. Recebi notícia segura que anda uma destruição horrível na mata, diz que mataram bicho e árvore aos milhares, falaram que até índio eles estão querendo matar, eu tenho que ir lá ajudar.” (NUNES, 2005, p. 32).

Em um paralelo de valores é possível apresentar o personagem Inventor por ser um homem simples, que se dedicava a criar banheiras, que pudessem transformar sentimentos ruins em atitudes boas. É uma oposição ao sistema capitalista porque não objetiva o acúmulo de riquezas, mas sim acabar com as aflições humanas decorrentes das problemáticas sociais como, por exemplo: a fome.

Ai a senhora deita na banheira. Se concentra. Resolve que vai transformar a sua mágoa numa pesquisa científica, ou num belo livro, ou numa descoberta médica. - Riu: - Imagina a senhora usando aquela força toda da sua mágoa pra querer acabar com o câncer? ou pra acabar com a fome que vai pelo mundo? (NUNES, 2005, p. 70).

Além do mais, verifica-se na narrativa que os valores identitários dos indivíduos advêm de um processo educativo obtido principalmente pelas instituições familiares e escolares. Frutos de uma sociedade patriarcal esses valores tendem a ser repassados para as novas gerações através da figura paterna. "O Pai é a palavra de Poder. O repetidor das estruturas ideológicas montadas." (SANDRONI, 1987, p. 75). Dessa forma, as crianças quando nascem já são inseridas em um ambiente marcado pelo autoritarismo e individualismo capitalista onde cabe apenas a reprodução das práticas já existentes.

A obra $O$ Sofá Estampado em um dialógo entre Vítor e seu Pai confirma o exposto: “[...] já tinha dito que não queria ser vendedor de carapaça ---- Você não vai ser vendedor de carapaça, você vai trabalhar na minha indústria, é diferente. Você vai começar vendendo, depois vai se encarregar da fabricação, depois..." (NUNES, 2005, p. 43).

De acordo com Sandroni (1987, p. 74) a família e a escola são, portanto, "agentes privilegiados da opressão institucionalizada que o adulto exerce sobre a criança sob o disfarce da proteção." Na escola além da superioridade do professor, as crianças se deparam com o universo da língua, um mundo desconhecido que lhes são impostos desde cedo.

Como forma de transgredir as convenções sociais, no desfecho final da narrativa, 


\section{Revista de Estudos Acadêmicos de Letras}

Vítor, informa a sua família que já havia decidido o que fazer da vida: seguir os passos de sua avó. O protagonista não assumiu o seu posto na indústria familiar como ordenado pelo pai e passou a se dedicar as causas sociais. A opção de vida que fez a exemplo das atitudes de sua Avó foi o que permitiu a resolução dos seus conflitos internos.

A alegoria é utilizada na obra $O$ Sofá Estampado para oportunizar a compreensão das causas e efeitos do sistema capitalista na sociedade pós-moderna. Nesse sentido, a literatura produzida por Lygia Bojunga Nunes, exerce uma função emancipatória, porque não aliena, mas ajuda crianças, adolescentes e adultos a organizar o seu plano interior e a refletir sobre a realidade imediata que as circunda. Isso ocorre porque a perspectiva trazida pela narrativa se confronta com a do leitor, de modo que, a partir daí, delineiam-se novos sentidos.

\section{Consideraçãos finais}

O processo de modernização provocou modificações na estrutura da sociedade capitalista. Em função disso, no período contemporâneo nada mantém a forma por muito tempo, estamos diante de um espaço fluído, o que implica a convivência do indivíduo com o indeterminado.

Por efeito, houveram mudança nas produções literárias do gênero infantojuvenil, visto que até a década de 60 apresentavam, apenas, intenções pedagógicas. Após o período destacado, surgiram escritores, como Lygia Bojunga Nunes, que passaram a produzir obras estabelecendo relações com o contexto, com o propósito de favorecer ao leitor a reconstrução das ideologias construídas pelo sistema capitalista.

A obra $O$ Sofá Estampado foi produzida na década de 80, mas apresenta elementos que dialogam com a atualidade permitindo fazer as seguintes considerações: o capitalismo determina as regras da produtividade das mercadorias, da distribuição da renda, bem como da conduta e do pensar humano.

O espaço-tempo é influenciado e transformado pelos modos de produção. As práticas cotidianas, dos indivíduos, estão direcionadas para a busca de melhores condições financeiras com o intuito de conquistar posições de destaque no meio de vivencia, consumo de objetos diversos e acúmulo patrimonial.

A ideia de satisfação pessoal está atrelada, muitas vezes, ao consumismo desmedido. Sobretudo, as disparidades das classes socioeconômicas existentes em decorrência da centralização do capital, fator este que coexiste ao sistema capitalista, impede a posse de bens em situação de igualdade. 
As práticas que se destinam a solucionar a problemática da diferença são restritas, por consequência as ações diárias estão arraigadas ao aspecto material, o que naturaliza as crises socioculturais, exaltando a necessidade de se intensificar as atitudes de solidariedade humana.

Dessa maneira, foi possível contribuir com a discussão em torno das relações sociais e o capitalismo na modernidade, enfocando os valores individualistas existentes e a oportunidade de realizar mudanças que possam proporcionar medidas direcionadas ao bemestar da coletividade, bem como ao resgate da afetividade em primeiro lugar para a construção de uma sociedade mais harmônica.

\section{Referências:}

BAUMAN, Z. Identidade; entrevista a Benedetto Vecchi. Rio de Janeiro: Zahar, 2005. . Modernidade Líquida. Rio de Janeiro: Jorge Zahar, 2001.

. Modernidade e Ambivalência. Rio de Janeiro: Jorge Zahar, 1999.

GIDDENS, A. As consequências da modernidade. São Paulo: Editora UNESP, 1991.

LAJOLO, M; ZILBERMAN, R. Literatura Infantil Brasileira: História e Histórias. 6 ed. São Paulo: Ática, 2002.

MARX, K. O capital. 7. ed., Rio de Janeiro: CTC, 1982.

NUNES, L. B. O Sofá Estampado. Motivos decorativos: 31 ed., Rio de Janeiro: Casa Lygia Bojunga, 2005.

QUINTANEIRO, T.; BARBOSA, M. L. O.; OLIVEIRA, M. G. M.. Um toque de clássicos: Marx, Durkheim e Weber. 2 ed., Belo Horizonte: UFMG, 2003.

ROSSLER, J. H. O desenvolvimento do psiquismo na vida cotidiana: aproximações entre a psicologia de Alexis N. Leontiev e a teoria da vida cotidiana de Agnes Heller. Cad. CEDES. Centro de Estudos Educação e Sociedade, Campinas, v. 24, n. 62, p. 100-116, abr. 2004. ISSN 0101-3262. Disponível em: http://www.cedes.unicamp.br. Acesso em: 09 Jan. 2017.

SANDRONI, L. De Lobato a Bojunga: as reinações renovadas. Rio de Janeiro: Agir,1987. 